\title{
Reproductive and Life History Parameters of Wild Female Macaca assamensis
}

\author{
Ines Fürtbauer • Oliver Schülke • \\ Michael Heistermann • Julia Ostner
}

Received: 9 October 2009 / Accepted: 26 November 2009 /

Published online: 14 May 2010

(C) The Author(s) 2010. This article is published with open access at Springerlink.com

\begin{abstract}
Information on basic reproductive parameters and life-history traits is crucial for the understanding of primate evolution, ecology, social behavior, and reproductive strategies. Here, we report $4 \mathrm{yr}$ of data on reproductive and life-history traits for wild female Assamese macaques (Macaca assamensis) at Phu Khieo Wildlife Sanctuary, northeastern Thailand. During 2 consecutive reproductive seasons, we investigated reproductive behavior and sexual swelling size in 16 females and collected 1832 fecal samples. Using enzyme immunoassays, we measured fecal estrogen and progesterone metabolites to assess ovarian activity and timing of ovulation and to ascertain conceptions and pregnancies. Timing of reproduction was strictly seasonal (births: April-July, 86\% in April-June, $4 \mathrm{yr}, n=$ 29; conceptions: October-February, 65\% in December-January, 2 yr, $n=17$ ). Females showed no cyclic ovarian activity outside the mating season and conceived in their first or second cycle (mean: 1.2 cycles to conception, $n=13$ ). Gestation length was on average $164.2 \mathrm{~d}$ (range: $158-170, n=10$ ), and females had their first infant at an age of $5 \mathrm{yr}(n=4)$. Interbirth intervals were bimodally distributed, with females giving birth on average every 13.9 or 23.2 mo. Shorter interbirth intervals were linked to early parturition within the birth season. Most females displayed subcaudal sexual swellings which, however, did not reliably indicate female reproductive status or fertility. Overall, our results fall within the range of findings reported for other macaque species. These results thus add to the growing body of
\end{abstract}

\footnotetext{
I. Fürtbauer $(\bowtie) \cdot$ O. Schülke $\cdot$ J. Ostner

Courant Research Center Evolution of Social Behaviour, Georg August University Göttingen, 37077 Göttingen, Germany

e-mail: ifuertb@uni-goettingen.de

I. Fürtbauer $\cdot$ J. Ostner

Integrative Primate Socioecology Group, Max Planck Institute for Evolutionary Anthropology, 04103 Leipzig, Germany

I. Fürtbauer $\cdot$ M. Heistermann

Department of Reproductive Biology, German Primate Center, 37077 Göttingen, Germany
} 
information available for wild macaques, facilitating comparative studies for a better understanding of interspecific differences in social and reproductive patterns.

Keywords Assamese macaques · fecal hormone analysis · gestation length · interbirth interval $\cdot$ seasonality $\cdot$ sexual swellings

\section{Introduction}

The diversity and plasticity of primate life-history traits, e.g., age at first birth, gestation length, weaning age, interbirth interval, and underlying reproductive parameters, e.g., number of ovarian cycles to conception, timing of cyclic ovarian activity and reproduction, ovarian cycle characteristics, allow researchers to address questions relating to evolution, ecology, and social behavior (Dixon 1983; Hrdy and Whitten 1987; Kappeler and Pereira 2003; Lee and Kappeler 2003). In particular, sexual strategies are assumed to be moulded by life-history (Kappeler et al. 2003). Thus, investigation of female basic reproductive parameters and life-history traits is a crucial first step when studying reproductive strategies used by males and females, and when exploring how they are associated with each other.

Macaques provide ideal conditions for comparative studies concerning the linkage between life histories and reproductive strategies. All macaque species share basic patterns of social organization: They all live in multimale, multifemale groups and they mate promiscuously, males disperse, whereas females are philopatric (Thierry 2007). On the other hand, they vary in social and reproductive traits, e.g., the degree of seasonality, with births occurring year-round or being restricted to a few months; social structure, dominance relationships; mating patterns; and the development of sexual signals, e.g., sexual swellings, sex skin coloration, copulation calls, all of which may influence the reproductive strategies of both sexes (Dixon 1998; van Noordwijk and van Schaik 2004).

Although the number of studies on macaques steadily increases, some species remain virtually unexplored. Moreover, owing to the difficulties of collecting data from naturally reproducing wild populations, some species are exclusively investigated under captive or free-ranging conditions. However, studies on reproductive and life-history parameters of wild individuals are crucial because it is well known that provisioning can influence reproductive physiology leading, for instance, to an acceleration of puberty and thus earlier age at first reproduction, e.g., Macaca fuscata: Takahata et al. (1998); Papio hamadryas: Zinner et al. (1994) or to a shortening of interbirth intervals (Takahata et al. 1998) compared to the situation found in naturally reproducing populations in the wild. Further, non-natural conditions may blur the degree of reproductive seasonality, e.g., females may cycle and breed throughout the year in captivity, whereas in the wild reproduction of the same species may be restricted to a defined period (Brockman and van Schaik 2005).

We investigated female reproductive parameters and life-history traits in a little known species, the Assamese macaque (Macaca assamensis) applying noninvasive hormone analyses. Assamese macaques are sexually dimorphic, breed seasonally (Bernstein and Cooper 1999; Ostner et al. 2008) and, like other macaques, live in multimale-multifemale groups with female philopatry and male dispersal. They are 
most closely related genetically to Tibetan macaques (Hoelzer and Melnick 1996) and have been classified as a species with a rather relaxed dominance style (Bernstein and Cooper 1999; Cooper and Bernstein 2002; Thierry et al. 2000). However, to our knowledge, apart from 1 study on female menstrual cycle patterns in captive Assamese macaques (Wehrenberg et al. 1980), no data are currently available on female reproductive parameters and life-history traits in this species. Here, we report for the first time data on breeding seasonality, i.e., timing of conceptions and distribution of births, female age at first birth, number of cycles to conception, gestation length, interbirth interval, and sexual swelling patterns obtained from a naturally reproducing wild Assamese macaque population living in northeastern Thailand.

\section{Methods}

\section{Study Site and Subjects}

We conducted the study between 2006 and 2009, including collection of detailed behavioral data and fecal samples during 2 complete mating seasons (MS, October to early February) and one nonmating season (NMS, mid-February to September), at the Phu Khieo Wildlife Sanctuary (PKWS, 157,300 ha, $16^{\circ} 5^{\prime}-35^{\prime} \mathrm{N}, 101^{\circ} 20^{\prime}-55-\mathrm{E}$, 300-1300 masl), northeastern Thailand, which consists of dry evergreen forest with patches of dry dipterocarp forest and bamboo stands (Borries et al. 2002). We collected data from a fully habituated group of Assamese macaques consisting of 53 individuals (12 adult females) during the MS 2007/2008 and 55 individuals (14 adult females) during the MS 2008/2009. In total, we collected fecal samples and data on sexual swellings from 16 females (11 multiparous, 4 primiparous, and 1 nulliparous females), 8 individuals being followed in each season. We selected females which, based on their reproductive history, were considered most likely to conceive in the respective MS. One female disappeared around the estimated date of parturition in June 2008, and 1 pregnant female died in March 2009. Demographic data, i.e., births and deaths for all individuals, were available from May 2006 through August 2009.

Fecal Sample Collection and Hormone Analyses

We collected and analyzed a total of 1832 fecal samples from 16 focal females. To characterize ovarian cycle patterns and assess timing of conception, we collected on average $4.6 \pm 0.5$ samples/wk from each focal individual during the 2 MSs. During the NMS we collected 4.7 samples/mo from all focal females, and, after females gave birth in 2008, we continued collection of feces from lactating females $(n=6 ; 1$ sample/wk) until the end of the MS 2008/2009. We collected samples directly after defecation, and placed a 5-15 g well homogenized portion in a tube labeled with subject ID and date, kept them cold using ice packs during the day, and froze them immediately at $-20^{\circ} \mathrm{C}$ after return to the field station. Samples were stored frozen until being shipped to the endocrine laboratory. We collected samples opportunistically throughout the day; however, we collected the majority of samples $(83 \%)$ between 08:00 and 13:00 h. 
For hormone analysis, we lyophilized and pulverized fecal samples and extracted an aliquot of $0.05-0.08 \mathrm{~g}$ with $3 \mathrm{ml}$ of $80 \%$ methanol in water by vortex-mixing for $10 \mathrm{~min}$ (Heistermann et al. 1995). After centrifugation (3000 rpm, $10 \mathrm{~min}$ ) of the fecal suspension, we decanted the supernatant into a glass tube and stored it at $-20^{\circ} \mathrm{C}$ until assay. We analyzed fecal extracts for concentrations of immunoreactive estrone

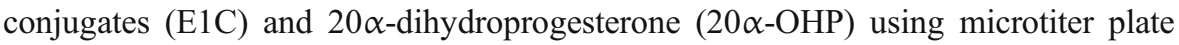
enzyme immunoassays (EIA), previously shown to reflect accurately female ovarian function in macaques and other primate species (Dubuc et al. 2009; Heistermann et al. 1995, 2001; Shideler et al. 1993). Details of the EIA procedures have been described previously by Heistermann and Hodges (1995, E1C) and Heistermann et al. $(1995,20 \alpha-\mathrm{OHP})$. Sensitivities of the assays at $90 \%$ binding were $1.0 \mathrm{pg}$ for E1C and $1.5 \mathrm{pg}$ for $20 \alpha-\mathrm{OHP}$. Intra- and interassay coefficients of variation, calculated from replicate determinations of high- and low-value quality controls, were $5.7 \%$ and $6.5 \%$ (high) and $8.8 \%$ and $14.5 \%$ (low) for E1C measurements and $7.5 \%$ and $13.1 \%$ (high) and $9.2 \%$ and $16.7 \%$ (low) for $20 \alpha-O H P$ determinations. All fecal hormone data are expressed as mass per gram of dry feces.

\section{Timing of Ovulation and Conception and Number of Cycles to Conception}

Because fecal estrogen profiles did generally not show a consistent preovulatory peak (see Results) for unknown reasons, we solely used the fecal progestogen profiles to determine the number of cycles to conception and the presumed day of ovulation and conception. The postovulatory progestogen rise is a reliable indicator that ovulation has indeed occurred, and this is the most widely used approach for determining timing of ovulation in primates (Barelli et al. 2007; Engelhardt et al. 2004; O’Neill et al. 2004; Strier and Ziegler 1997). As described in many other studies (Carosi et al. 1999; Engelhardt et al. 2004; Heistermann et al. 2008), we used the defined rise in fecal progestogen levels above a threshold of the mean \pm 2 SD of 5 preceding baseline values to indicate the onset of the postovulatory (luteal) phase of an ovarian cycle or the onset of gestation (indicated by maintenance of elevated luteal phase progestogen levels for $>4 \mathrm{wk}$ ). Levels below this threshold indicated the follicular phase of the cycle. On the basis of a time lag of about $2 \mathrm{~d}$ in the excretion of progesterone metabolites in the feces of macaques (Shideler et al. 1993), we considered d -3 relative to the day of the defined progestogen increase (d 0 ) as the most likely day of ovulation. Because of the possible variability in the temporal relationship between ovulation and the postovulatory fecal progestogen increase (Shideler et al. 1993), and because daily samples during the periovulatory period were not always available, data on the timing of ovulation/conception can be expected to include an error of $1-2 \mathrm{~d}$.

\section{Sexual Swellings}

Assamese macaque females exhibit subcaudal sexual swellings. We visually categorized swelling size on an almost daily basis using 5 categories ranging from 0 to 4 , defined as follows. $0=$ no swelling; $1=$ changes in the appearance of subcaudal skin (the skin becoming wrinkled and/or more visible); $2=$ slight swelling; 3 = small swelling, 4 = large swelling with lateral bumps (Fig. 1). 
Fig. 1 Subcaudal swelling size categories. $0=$ no swelling; $1=$ changes in the appearance of subcaudal skin (visibility; wrinkles); 2 = slight swelling; $3=$ small swelling; $4=$ large swelling with lateral bumps.

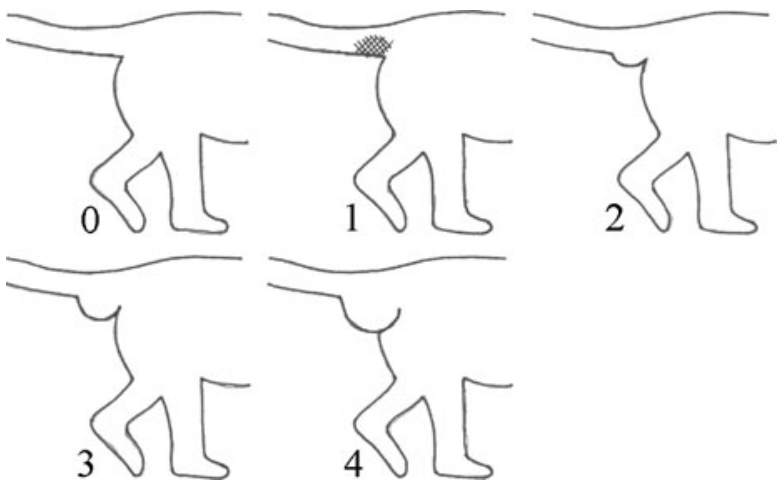

\section{Life-history Traits}

Age at First Birth We estimated age at first birth for primiparous females retrospectively based on body size comparisons with different age cohorts, which can be clearly distinguished owing to the strong reproductive seasonality.

Gestation Length We calculated gestation length in individual females as the interval between the hormonally determined day of conception and the observed day of parturition.

Interbirth Interval (IBI) and Postpartum Amenorrhea (PPA)

We calculated interbirth intervals in days and then converted them to months $(1 \mathrm{mo}=$ $30.4 \mathrm{~d}$ ) on the basis of observed parturitions. In cases where the exact day of parturition was unknown ( 9 of 24 births), we used the midpoint of the first and the last possible day of parturition (unknown period of max. $12 \mathrm{~d}$ ). We included only IBIs following a surviving offspring ( $>12 \mathrm{mo})$. We calculated the duration of PPA for females with 1-yr IBIs by counting the days between parturition and next conception. We applied binary logistic regression with SPSS 17.0 to analyze the relationship between the occurrences of $1-y$ r IBIs and the timing of parturitions within the birth seasons. We used the occurrence of 1-yr IBIs as the dependent, and the number of days between the first day of the first month in which births occur (April 1) and the date of parturition as the independent variable. The 1-sided significance level was set at $p<0.05$.

\section{Results}

\section{Breeding Seasonality}

Reproduction in Assamese macaques was highly seasonal. The period when conceptions occurred lasted from October to early February, with the vast majority of conceptions $(65 \%)$ confined to December and January $(n=17,2$ years; Fig. 2; 
Fig. 2 Monthly distribution of conceptions ( $n=17$; 15 females; 2 mating seasons) and births ( $n=29,15$ females; 4 birth seasons).

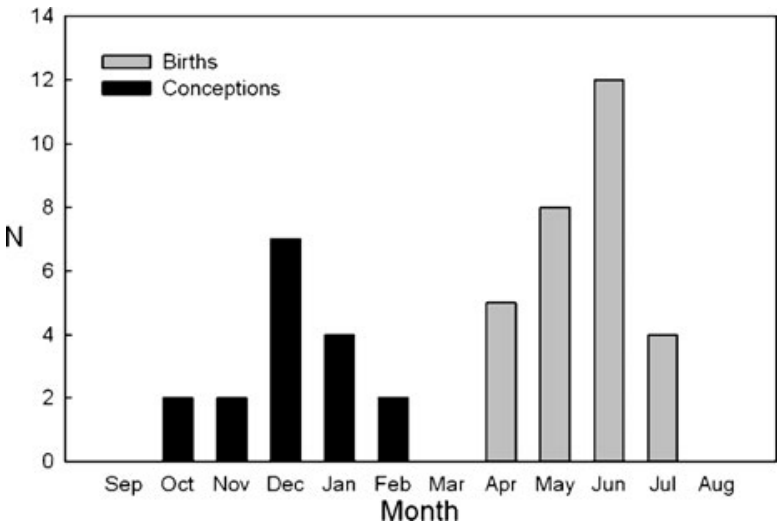

Table I). A total of 29 infants were born between 2006 and 2009 (Fig. 2). In 2006, 2007, and 2008, all infants were born between April and June, whereas in 20094 of 9 infants were also born in July. Thus, distribution of births within the 4 study years was highly skewed, with an overall of $69 \%$ of births being confined to May and June and $86 \%$ to the 3-mo period of April-June.

Female Reproductive Physiology

Seven of 8 focal females conceived in the MS 2007/2008, whereas in the MS 2008/ 2009 all 8 focal females became pregnant. In addition, in 20092 nonfocal females that had also conceived an infant in 2007/2008 gave birth.

Figure 3 shows 2 profiles of fecal E1C and $20 \alpha-\mathrm{OHP}$, covering the month before the mating season, i.e., September, the mating season, the period of gestation until parturition, and early lactation in 2 representative females. As can be seen in Fig. 3, and as evident from endocrine profiles in all other focal individuals, females did not show any cyclic ovarian activity before the onset of the mating season in October. Conception was clearly visible by a significant rise in fecal progestogen levels that

Table I Reproductive and life history parameters of wild female Assamese macaques

\begin{tabular}{|c|c|c|c|c|c|c|c|}
\hline Parameter & & Mean & $\mathrm{SD}$ & Median & Range & $n$ & Unit \\
\hline Gestation length & & 164.2 & 4.0 & 164.5 & $158-170$ & 10 & Days \\
\hline Interbirth interval $^{\mathrm{a}}$ & & - & - & 22.2 & $12.6-24.7$ & 12 & Months \\
\hline$\sim 1 \mathrm{yr}$ & & 13.9 & 0.9 & 14.2 & $12.6-14.9$ & 5 & Months \\
\hline$\sim 2 \mathrm{yr}$ & & 23.2 & 0.9 & 23.2 & $22.1-24.7$ & 7 & Months \\
\hline Cycles to conception & & 1.2 & 0.4 & 1 & $1-2$ & 13 & - \\
\hline Timing of conceptions & $\begin{array}{l}67 \% \text { in December/ } \\
\text { January }\end{array}$ & - & - & - & October-February & 17 & - \\
\hline Age at first birth & & 5 & - & 5 & - & 4 & Years \\
\hline Timing of births & $69 \%$ in May/June & 3 & - & 3 & 2-4 (April-July) & $4^{\mathrm{b}}$ & Months \\
\hline
\end{tabular}

\footnotetext{
${ }^{a}$ IBI follows a bimodal pattern

${ }^{\mathrm{b}} 4$ birth seasons (2006-2009; 29 births)
} 

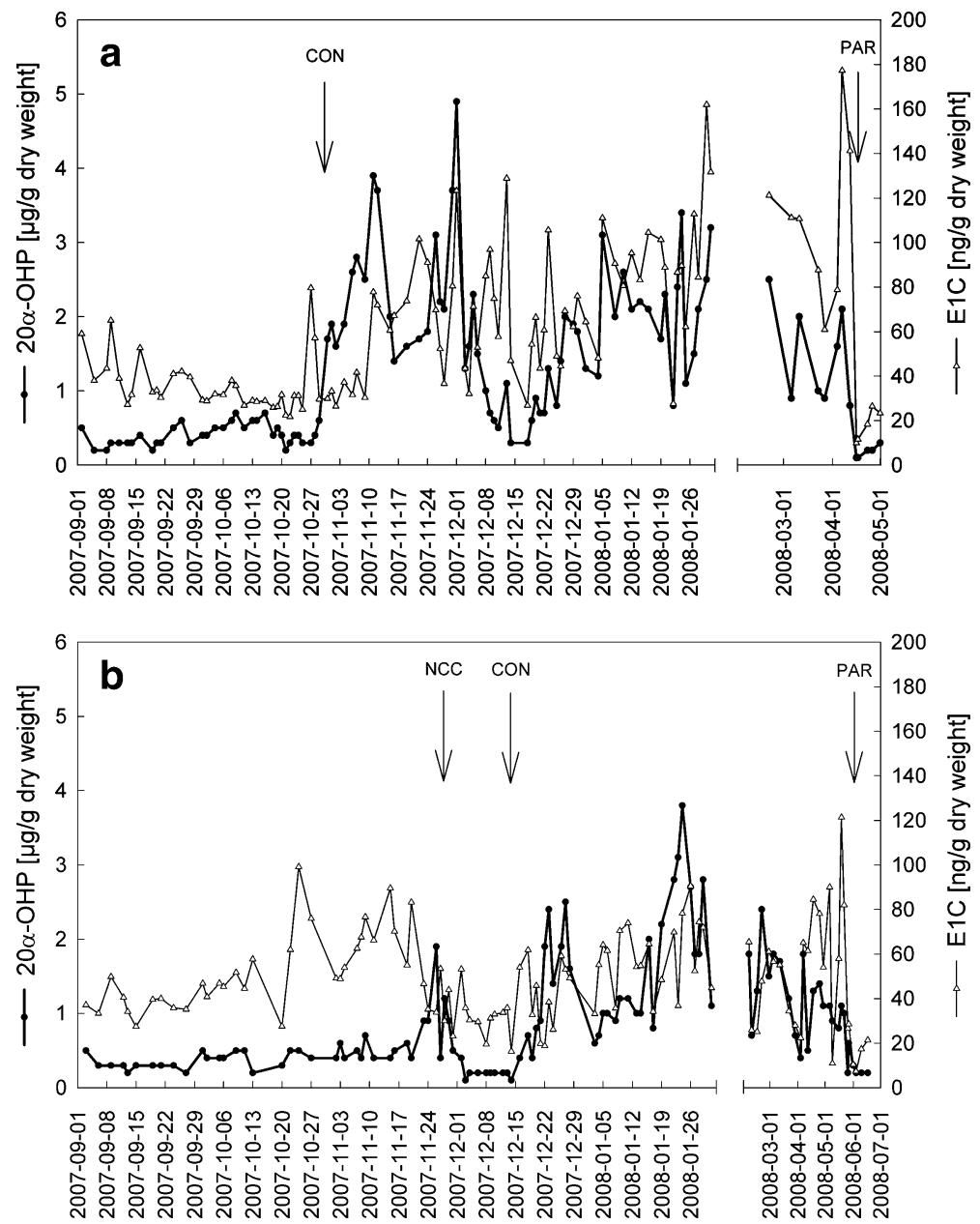

Fig. 3 Individual profiles of fecal immunoreactive progestogens $(20 \alpha-\mathrm{OHP})$ and estrogens (E1C) in 2 wild Assamese macaque females covering the period 1 mo before the onset of the mating season, the mating season, gestation, and early lactation, with conception occurring in the first (a) or second (b) ovarian cycle. $\mathrm{CON}=$ conception; $\mathrm{PAR}=$ parturition; $\mathrm{NCC}=$ non-conception cycle. Note the adjusted scale after the axis break.

remained elevated (above preconception levels) for the remainder of gestation. After parturition, progestogen levels dropped to baseline concentrations again and remained low during early lactation. In contrast to the progestogen profiles, the patterns of fecal estrogens were less clear. Specifically, a preovulatory estrogen peak was seen in some of the individuals (Fig. 3a), but not in others (Fig. 3b). In addition, although estrogen levels, on average, showed a modest increase during gestation, this was not seen in all focal females. Based on the hormonal data, ten out of the thirteen conceptions occurred during the first cycle (Fig. 3a), while the remaining three females conceived during their second cycle (Fig. 3b). For the 3 females that conceived in the second cycle, cycle length, based on the interval between 
successive fecal progestogen rises, was: 24,30 , and 38 days with an 11-, 15-, and 13-day luteal phase.

Gestation Length and Age at First Birth

For ten females for which the day of conception and the day of parturition were known, length of gestation averaged $164.2 \pm 4.0 \mathrm{~d}$ (median=164.5, $n=10$, range: $158-170)$.

Age at first birth was $5 \mathrm{yr}$ for all 4 primiparous females.

Interbirth Interval (IBI) and Infant Mortality

For 8 females we were able to calculate IBI $(n=12)$, either on the basis of observed parturitions $(n=10)$ or, for 2 females that disappeared before giving birth, assuming a gestation length of $164 \mathrm{~d}$. The distribution of IBI followed a bimodal pattern, with a

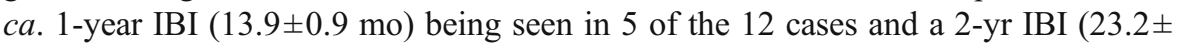
$0.9 \mathrm{mo}$ ) being observed in the remaining 7 cases (Fig. 4). Females that gave birth early in the birth season were more likely to exhibit a $1-\mathrm{yr}$ IBI $(\mathrm{B}=-0.04, \mathrm{SE}=0.03$, $\mathrm{df}=1$, Wald $\chi^{2}=2.91, p<0.05 ; 1$-sided), and we exclusively observed 1 -yr IBIs in multiparous females. PPA for 4 females with a 1-yr IBI ranged from 265 to $290 \mathrm{~d}$. Two of the 29 infants (6.9\%) born between 2006 and 2009 died at an age of 4 and 10 mo, respectively, and therefore, we did not include them in the IBI calculations.

\section{Sexual Swellings}

Of the 16 focal females, the majority $(n=13)$ displayed a sexual swelling, but females differed in maximum swelling size attained (Fig. 5), whereas 3 (cyclic) females showed no swelling around ovulation (Fig. 5a). Maximum swelling size for multiparous females $(n=11)$ ranged from 1 to 3 , i.e., multiparous females never reached category 4. Maximum swelling size for primiparous females $(n=4)$ was 4 in 3 cases, and 3 in 1 case. The only nulliparous (acyclic) female in this study attained swelling size category 2 . We could not detect any cyclic pattern in sexual swelling size and swellings did not deflate after conception (Fig. 5b, c). The timing of maximum swelling size attained varied among females, i.e., some females reached their maximum swelling before ( $n=7$; Fig. 5 b) and some ( $n=5$; Fig. 5 c) females after conception.

Fig. 4 Distribution of interbirth intervals in wild Assamese macaques ( $n=12,8$ females).

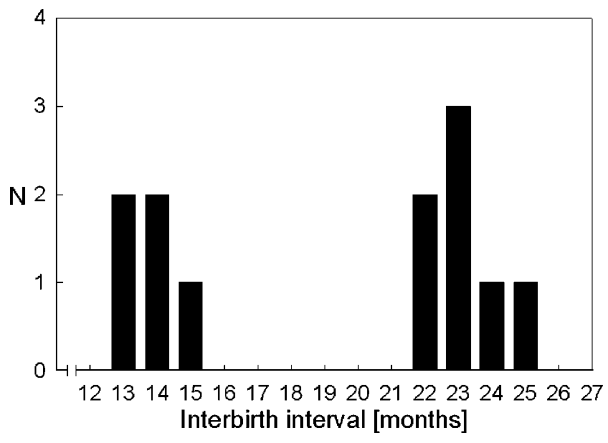


Fig. 5 Sexual swelling size (gray bars) in relation to fecal $20 \alpha$-OHP levels (solid line) and the timing of conception (arrow) in 3 wild Assamese macaque females. The figure illustrates the large variability in swelling patterns between females and the absence of a defined relationship between swelling size and female reproductive status.
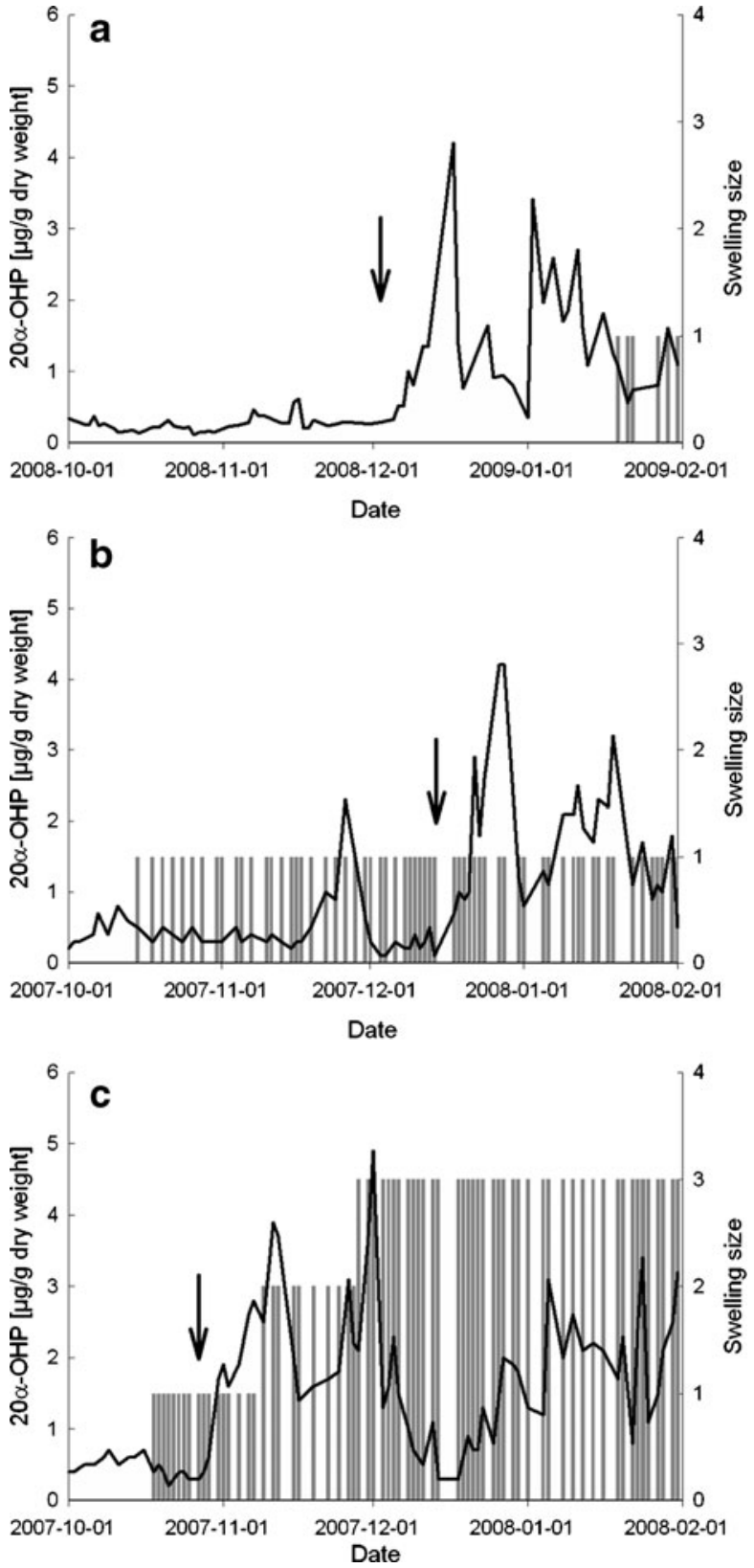

\section{Discussion}

We here describe for the first time female reproductive parameters and life-history traits in wild female Assamese macaques. We present data on reproductive seasonality, basic female reproductive physiology, gestation length, age at first birth, interbirth interval, and sexual swellings, derived from a naturally reproducing 
wild population. For most parameters, the values found for Assamese macaques fall into the range reported for other macaque species. The distribution of interbirth intervals and the large interindividual variability in swelling patterns, however, appear to deserve further attention.

\section{Reproductive Seasonality}

Seasonal timing of reproduction among macaques covers the entire range from yearround breeding, e.g., in pigtail macaques (Macaca nemestrina), to extreme seasonal reproduction in the Japanese macaque (Macaca fuscata; range across macaques: 46365 d; Nunn 1999a). Seasonal breeding implies physiological and behavioral transition from a nonreproductive to a reproductive state, i.e., females may show a change in reproductive cyclicity (Walker et al. 1983), likely caused by environmental factors (photoperiod, temperature, rainfall, food abundance; Brockman and van Schaik 2005).

In our study, $65 \%$ of conceptions were confined to December and January and $86 \%$ of births occurred within the 3-mo period of April-June, indicating a strict reproductive seasonality (sensu van Schaik et al. 1999) in Assamese macaques. Similar to Japanese (Hill 1997) and Barbary macaques (Ménard and Vallet 1996), Assamese macaques at Phu Khieo Wildlife Sanctuary live in a markedly seasonal habitat with seasonal changes in rainfall (Grassman et al. 2005) and food availability (Koenig et al. 2004, Schülke et al. unpublished). However, a fine-grained analysis of potential triggers for the timing of reproduction is pending.

\section{Female Reproductive Physiology}

As in previous studies on various primate taxa (Barelli et al. 2007; Carosi et al. 1999; Dubuc et al. 2009; Engelhardt et al. 2004; Heistermann et al. 2008; Higham et al. 2009 Ziegler et al. 2000), measurement of fecal progestogen excretion proved to be a reliable tool for the assessment of female reproductive status, including the timing of ovulation and conception in Assamese macaques. By contrast, the measurement of fecal estrogens in Assamese macaques appears to be less useful in assessing female ovarian function because estrogen profiles often lacked a clear preovulatory peak and showed no marked elevation in levels during gestation. The reason why our results for Assamese macaques differ in this respect from those reported for other macaque species (Brauch et al. 2007; Dubuc et al. 2009; Engelhardt et al. 2004; Fujita et al. 2001) is not clear. Given that it is unlikely that Assamese macaques differ in their mechanisms of hormonal regulation of the ovarian cycle and pregnancy from other macaques, our finding of less informative fecal estrogen profiles is likely related to species differences in estrogen metabolism and pattern of excretion or assay methodology. In this respect there are 4 nonmutually exclusive potential explanations. First, in Assamese macaques estrogens may be predominantly excreted into the urine rather than into the feces, rendering fecal measurements less informative. Second, measurement of other estrogen metabolites than the one measured here might be more adequate for monitoring estrogen excretion in this species. However, analysis of estradiol and total estrogens in a subset of cycles did not show better profiles (data not shown). 
Third, the E1C antibody used here might have potentially cross-reacted with fecal compounds unrelated to estrogen secretory dynamics, thereby confounding an existing pattern. Last but not least, given the short-term nature of the preovulatory estrogen peak, it cannot be excluded that in some females the estrogen peak was just missed because daily samples were often not available during the periovulatory period. A study on estrogen metabolism and excretion, including HPLC analysis to help clarify 1) the identity of the major fecal estrogen metabolites excreted in female Assamese macaques and 2) the potential for co-measurement of nonestrogenic compounds by any given estrogen assay used would be a useful step toward resolving this issue in the future.

Consistent with the strong reproductive seasonality, females showed a typical hormonal pattern, with absence of cyclic ovarian activity during the nonmating season ("flat liner") and resumption of ovarian cycles during the mating season, a phenomenon also seen in other primate species with a highly seasonal reproduction, e.g., Macaca sylvanus: Moehle et al. (2005); Semnopithecus entellus: Ziegler et al. (2000). The lack of ovulatory cycles during the nonmating season was seen irrespective of whether or not females were nursing an infant. This further underscores the impact of the observed seasonality on female reproductive physiology in this species.

Like other seasonally breeding macaque species, e.g., Macaca sylvanus: Küster and Paul (1984); Moehle et al. (2005); Macaca mulatta: Lindburg (1971); Macaca fuscata: Takahata (1980), Assamese macaque females conceived mostly during the first cycle of the mating season. Hence, ovarian cycle characteristics, i.e., the length of the ovarian cycle, and its component phases, could be determined only for the few females that conceived in their second cycle, and was 24, 30, and $38 \mathrm{~d}$ (with 11-, 15-, and 13-d luteal phases). These data fall well into the range of observed cycle lengths in macaques (26.4-38.0 d; Thierry 2007) and compare well with cycle length data of $32 \pm 2 \mathrm{~d}$ (divided into a $16 \pm 1 \mathrm{~d}$ follicular phase and a $16 \pm 1 \mathrm{~d}$ luteal phase) reported by Wehrenberg et al. (1980) for captive individuals based on blood hormone analysis.

Gestation among macaques is relatively constant and ranges from 160 to $182 \mathrm{~d}$ (Kappeler and Pereira 2003), and female age at first birth in macaques, based on captive and wild data, ranges from 3.5 to $6.5 \mathrm{yr}$ (Melnick and Pearl 1987). An average gestation length of $164 \mathrm{~d}$ and an age of first reproduction of $5 \mathrm{yr}$, as found for Assamese macaques here, fits well into the reported ranges.

\section{Interbirth Interval (IBI)}

The IBIs in Assamese macaques are bimodally distributed, with females giving birth on average 14 mo or 23 mo after the previous birth, i.e., the next year or after 2 yr (range across macaques: 12-24 mo; Kappeler and Pereira 2003). The IBI is made up of 3 components: gestation length (GL), postpartum amenorrhea (PPA), and the duration of ovarian cycling to conception (DC). Because GL in any primate species is relatively invariable (Dixon 1998), differences in IBI within a species as reported here for Assamese macaques can be caused only by differences in the duration of PPA and/or DC (provided that under natural conditions a female would inevitably conceive). Most Assamese macaque females conceived in their first cycle, 
i.e., DC is minimized. PPA for 4 females with a 1-yr IBI ranged from 265 to $290 \mathrm{~d}$ (birth until next conception), and thus was relatively constant. This indicates that the time that a female needs to resume cycling after giving birth is restricted owing to inhibitory effects of lactation (McNeilly 2001) and maternal body condition. Concerning the latter, studies on several primate taxa have shown that females need to attain a critical body weight before they can resume ovarian cycling, e.g., Papio anubis: Bercovitch (1987); Propithecus verrauxi verrauxi: Lewis and Kappeler (2005); Macaca nemestrina: Maninger et al. (2000); Semnopithecus entellus: Ziegler et al. (2000); Homo sapiens: Frisch and McArthur (1974). In line with this, nutritional conditions appear to affect the length of the IBI (Borries et al. 2001; Takahata et al. 1998). Similarly, it has been shown that infants need to reach a minimum body mass threshold for weaning (Lee 1996, 1999; Lee et al. 1991). Accordingly, the timing of parturition within the birth season may play an important role, simply because females that give birth early in the birth season have more time to reach the conditions required to resume cyclic ovarian activity in the following mating season. Females should therefore be more likely to have an infant in the consecutive year, and thus a short IBI, when they give birth early in the birth season. Our results support this hypothesis because the occurrence of 1-yr IBIs was significantly linked to early parturition within the birth season.

In addition, owing to lactational constraints on ovarian activity, the loss of an infant may shorten the length of the IBI, e.g., Papio cynocephalus: Altmann et al. (1977); Trachypithecus leucocephalus: Jin et al. (2009); Macaca maurus: Okamoto (2000); Mandrillus sphinx: Setchell et al. (2002); Macaca fuscata: Tanaka et al. (1970); Macaca thibetana: Zhao and Deng (1988); Papio hamadryas: Zinner et al. (1994). This effect may be stronger in nonseasonal species than in strictly seasonal species, in which the timing of infant loss may be crucial: if the infant dies late in the mating season or even after the end of the mating season, a female may not be able to resume cycling. This may lead to infanticide being a favorable strategy for males only during a specific time window. In this study, infant mortality was low (6.9\%), and only 1 of 61 -yr IBIs was preceded by the loss of a 4-mo-old infant at the beginning of the mating season for an unknown reason. Another infant died at an age of 10 mo during the nonmating season, and this did not result in a shorter IBI.

Although the loss of an infant may shorten the length of the IBI, depending on the timing of the loss, it does not appear to be the ultimate cause for the occurrence of 1yr IBIs in female Assamese macaques. This and the linkage between 1-yr IBIs and the timing of parturition within the birth season, in turn, suggest that the IBIs are, to some extent, influenced by physiological constraints that may be partly linked to the strong reproductive seasonality. However, long-term data are needed to investigate the potential impact of age, rank, and ecological factors on the distribution of 1- and 2-yr IBIs in this species (Borries et al. 2001; Robbins et al. 2007; Setchell et al. 2002).

\section{Sexual Swellings}

Coloration and swelling of sex skin during the menstrual cycle are found in many Old World primate species, most of them living in multimale-multifemale groups (Clutton-Brock and Harvey 1976; Nunn et al. 2001). Changes in size and coloration 
of female sex skin swellings may reflect changes in estrogen and progesterone secretion, i.e., the E/P ratio, with ovulation usually occurring during the period of maximum swelling size (Brauch et al. 2007; Deschner et al. 2003; Higham et al. 2008). Sex skin swellings have evolved at least 3 times independently in Old World primates (Dixon 1983; Hrdy and Whitten 1987), and several species display an exaggeration of this trait (Nunn 1999b). Macaque species exhibit pronounced variation in size and coloration of sex skin swellings. Large and pinkish swellings involving skin in the subcaudal, circumanal, paracallosal, vulval, and clitoral areas occur in species of the silenus-sylvanus group, whereas members of the fascicularis, and the sinica-arctoides groups show reduced swellings (Dixon 1983, 1998). Interestingly, in some macaque species adolescent females exhibit larger swellings than do adult females (Anderson and Bielert 1994; Dixon 1983), and swellings or sex skin color changes during early pregnancy (post-conception swellings) are common, e.g., Macaca fascicularis: Engelhardt et al. (2007); Macaca sylvanus: Moehle et al. (2005); reviewed in Hrdy and Whitten (1987). Not only the appearance of sexual swellings but also their functional significance varies among macaque species, i.e., swellings may convey reliable information on female reproductive state, e.g., Macaca sylvanus: Brauch et al. (2007), or, in contrast, may have limited, e.g., Macaca fascicularis: Engelhardt et al. (2005) or no apparent signaling content, e.g., Macaca thibetana: Li et al. (2005).

As predicted for a seasonal species (Dixon 1998; cf. van Schaik et al. 1999), Assamese macaque females did not exhibit prominent sexual swellings. We found remarkable interindividual differences in swelling patterns that mostly concur with van Noordwijk's (1985) findings in female long-tail macaques. The maximum swelling size attained varied among females, and some females did not show swellings at all, despite the fact that they were conceiving and thus reproductively normal. Young females showed swellings of larger maximum size, and may have a swelling a year before their first conception (Fürtbauer, pers. obs.). As we found neither apparent cyclic size changes nor a link between swelling patterns and hormonal profiles/timing of conceptions, the observed swelling characteristics suggest that, in contrast to macaque species with a pronounced swelling, the subcaudal swellings in female Assamese macaques do not reliably indicate female reproductive status and fertility, and may simply be a relic of an ancestral trait. It may be possible, however, that the method used in this study-visual judgment instead of video imaging - did not pick up on very subtle changes in sexual swelling patterns.

\section{Conclusions and Implications for Female Reproductive Strategies}

In summary, the reproductive parameters and life-history traits reported in the present study for female Assamese macaques mostly resemble findings for other macaque species. Although this is not surprising, the information generated here is useful in helping to complete the data base on reproductive and life-history traits in wild macaques and thus facilitating species comparisons. More importantly, however, knowledge in this area will also be crucial for future studies investigating the reproductive biology of Assamese macaques. In this respect, the finding of a strong reproductive seasonality with a high degree of clustering in timing of 
conceptions, and thus suggesting female reproductive synchrony, is likely to influence strongly male and female reproductive strategies and their significance on reproductive success. Because asynchrony within estrus synchrony may occur (Pereira 1991), however, a thorough analysis of the temporal distribution of fertile phases together with male and female sexual activity is needed to investigate female reproductive strategies.

Acknowledgments We thank the National Research Council of Thailand (NRCT) and the Department of National Parks, Wildlife and Plant Conservation (DNP) for permission (no. 0004.3/3618) to conduct this study. We thank J. Prabnasuk, K. Nitaya, and K. Kreetiyutanont (Phu Khieo Wildlife Sanctuary) for their cooperation and permission to conduct this study. We thank A. Koenig and C. Borries (Stony Brook University), who developed the field site at Huai Mai Sot Yai, for their support. We thank Andrea Heistermann and Jutta Hagedorn for technical assistance in hormone analysis, and M. Swagemakers, D. Bootros, T. Kilawit, A. Chunchaen, P. Saisawatdikul, S. Jomhlotwong, S. Rogahn, and W. Nuagchiyos for their help in the field. We thank J. Setchell and 2 anonymous referees for their valuable comments on the manuscript. We also thank N. Bhumpakphan, W. Eiadthong (Kasetsart University), and W. Brockelman (Mahidol University) for their support and cooperation. The project was supported with funds from the National Geographic Society, Max-Planck Society and the German Initiative of Excellence.

Open Access This article is distributed under the terms of the Creative Commons Attribution Noncommercial License which permits any noncommercial use, distribution, and reproduction in any medium, provided the original author(s) and source are credited.

\section{References}

Altmann, J., Altmann, S. A., Hausfater, G., \& McCuskey, S. A. (1977). Life history of yellow baboons: physical development, reproductive parameters, and infant mortality. Primates, 18, 315-330.

Anderson, C. M., \& Bielert, C. F. (1994). Adolescent exaggeration in female catarrhine Primates. Primates, 35, 283-300.

Barelli, C., Heistermann, M., Boesch, C., \& Reichard, U. H. (2007). Sexual swellings in wild whitehanded gibbon females (Hylobates lar) indicate the probability of ovulation. Hormones and Behavior, $51,221-230$.

Bercovitch, F. B. (1987). Female weight and reproductive condition in a population of olive baboons (Papio anubis). American Journal of Primatology, 12, 189-195.

Bernstein, I. S., \& Cooper, M. A. (1999). Dominance in Assamese macaques (Macaca assamensis). American Journal of Primatology, 48, 283-289.

Borries, C., Koenig, A., \& Winkler, P. (2001). Variation of life history traits and mating patterns in female langur monkeys (Semnopithecus entellus). Behavioral Ecology and Sociobiology, 50, 391-402.

Borries, C., Larney, E., Kreetiyutanont, K., \& Koenig, A. (2002). The diurnal primate community in a dry evergreen forest in Phu Khieo Wildlife Sanctuary, Northeast Thailand. Natural History Bulletin of the Siam Society, 50, 75-88.

Brauch, K., Pfefferle, D., Hodges, K., Möhle, U., Fischer, J., \& Heistermann, M. (2007). Female sexual behavior and sexual swelling size as potential cues for males to discern the female fertile phase in free-ranging Barbary macaques (Macaca sylvanus) of Gibraltar. Hormones and Behavior, 52, 375383.

Brockman, D. K., \& van Schaik, C. P. (2005). Seasonality and reproductive function. In D. K. Brockman \& C. P. van Schaik (Eds.), Seasonality in primates: Studies of living and extinct human and nonhuman primates (pp. 269-305). Cambridge: Cambridge University Press.

Carosi, M., Heistermann, M., \& Visalberghi, E. (1999). Display of proceptive behaviors in relation to urinary and fecal progestin levels over the ovarian cycle in female tufted capuchin monkeys. Hormones and Behavior, 36, 252-265.

Clutton-Brock, T. H., \& Harvey, P. H. (1976). Evolutionary rules and primate societies. In P. P. G. Bateson \& R. A. Hinde (Eds.), Growing points in ethology (pp. 195-237). Cambridge: Cambridge University Press. 
Cooper, M. A., \& Bernstein, I. S. (2002). Counter aggression and reconciliation in Assamese macaques (Macaca assamensis). American Journal of Primatology, 56, 215-230.

Deschner, T., Heistermann, M., Hodges, J. K., \& Boesch, C. (2003). Timing and probability of ovulation in relation to sex skin swelling in wild West African chimpanzees, Pan troglodytes verus. Animal Behaviour, 66, 551-560.

Dixon, A. F. (1983). Observations on the evolution and behavioural significance of "sexual skin" in female primates. Advances in the Study of Behavior, 13, 63-106.

Dixon, A. F. (1998). Primate sexuality: Comparative studies of the prosimians, monkeys, apes, and human beings. Oxford: Oxford University Press.

Dubuc, C., Brent, L. J. N., Accamando, A. K., Gerald, M. S., MacLarnon, M., Semple, S., et al. (2009). Sexual skin color contains information about the timing of the fertile phase in free-ranging rhesus macaques. International Journal of Primatology. doi:10.1007/s10764-009-9369-7.

Engelhardt, A., Pfeifer, J. B., Heistermann, M., Niemitz, C., van Hooff, J. A. R. A. M., \& Hodges, J. K. (2004). Assessment of female reproductive status by male longtailed macaques, Macaca fascicularis, under natural conditions. Animal Behaviour, 67, 915-924.

Engelhardt, A., Hodges, J. K., Niemitz, C., \& Heistermann, M. (2005). Female sexual behavior, but not sex skin swelling is a reliable indicator for the timing of the fertile phase in wild long-tailed macaques (Macaca fascicularis). Hormones and Behavior, 47, 195-204.

Engelhardt, A., Hodges, J. K., \& Heistermann, M. (2007). Post-conception mating in wild long-tailed macaques (Macaca fascicularis): characterization, endocrine correlates and functional significance. Hormones and Behavior, 51, 3-10.

Frisch, R. E., \& McArthur, J. W. (1974). Menstrual cycles: fatness as a determinant of minimum weight for height necessary for their maintenance or onset. Science, 185, 949-951.

Fujita, S., Mitsunaga, F., Sugiura, H., \& Shimizu, K. (2001). Measurement of urinary and fecal steroid metabolites during the ovarian cycle in captive and wild Japanese macaques, Macaca fuscata. American Journal of Primatology, 53, 167-176.

Grassman, L. I., Jr., Tewes, M. E., Silvy, N. J., \& Kreetiyutanont, K. (2005). Spatial organization and diet of the leopard cat (Prionailurus bengalensis) in north-central Thailand. Journal of Zoology, London, $266,45-54$.

Heistermann, M., \& Hodges, K. (1995). Endocrine monitoring of the ovarian cycle and pregnancy in the saddle-back tamarin (Saguinus fuscicollis) by measurement of steroid conjugates in urine. American Journal of Primatology, 35, 117-127.

Heistermann, M., Finke, M., \& Hodges, J. K. (1995). Assessment of female reproductive status in captivehoused Hanuman langurs (Presbytis entellus) by measurement of urinary and fecal steroid excretion patterns. American Journal of Primatology, 37, 275-284.

Heistermann, M., Uhrigshardt, J., Husung, A., Kaumanns, A., \& Hodges, J. K. (2001). Measurement of faecal steroid metabolites in the lion-tailed macaque (Macaca silenus): a non-invasive tool for assessing female ovarian function. Primate Report, 59, 27-42.

Heistermann, M., Brauch, K., Möhle, U., Pfefferle, D., \& Hodges, K. (2008). Female ovarian cycle phase affects the timing of male sexual activity in free-ranging Barbary macaques (Macaca sylvanus) of Gibraltar. American Journal of Primatology, 70, 44-53.

Higham, J. P., MacLarnon, A. M., Ross, C., Heistermann, M., \& Semple, S. (2008). Baboon sexual swellings: information content of size and color. Hormones and Behavior, 53, 452-462.

Higham, J. P., Semple, S., MacLarnon, A., Heistermann, M., \& Ross, C. (2009). Female reproductive signaling, and male mating behavior, in the olive baboon. Hormones and Behavior, 55, 60-67.

Hill, D. A. (1997). Seasonal variation in the feeding behavior and diet of Japanese macaques (Macaca fuscata yakui) in lowland forest of Yakushima. American Journal of Primatology, 43, 305-323.

Hoelzer, G. A., \& Melnick, D. J. (1996). Evolutionary relationships of the macaques. In J. E. Fa \& D. G. Lindburg (Eds.), Evolution and ecology of macaque societies (pp. 3-19). New York: Cambridge University Press.

Hrdy, S. B., \& Whitten, P. L. (1987). Patterning of sexual activity. In B. B. Smuts, D. L. Cheney, R. M. Seyfarth, R. W. Wrangham, \& T. T. Struhsaker (Eds.), Primate societies (pp. 370-384). Chicago: University of Chicago Press.

Jin, T., Wang, D. Z., Zhao, Q., Yin, L. J., Qin, D. G., Ran, W. Z., et al. (2009). Reproductive parameters of wild Trachypithecus leucocephalus: seasonality, infant mortality and interbirth interval. American Journal of Primatology, 71, 558-566.

Kappeler, P. M., \& Pereira, M. E. (2003). Primate life histories and socioecology (p. 416). Chicago: University of Chicago Press. 
Kappeler, P. M., Pereira, M. E., \& van Schaik, C. P. (2003). Primate life histories and socioecology. In P. M. Kappeler \& M. E. Pereira (Eds.), Primate life histories and socioecology (pp. 1-20). Chicago: University of Chicago Press.

Koenig, A., Borries, C., Suarez, S., Kreetiyutanont, K., \& Prabnasuk, J. (2004). Socio-ecology of Phayre's leaf monkeys (Trachypithecus phayrei) at Phu Khieo Wildlife Sanctuary. Journal of Wildlife in Thailand, 12, 150-163.

Küster, J., \& Paul, A. (1984). Female reproductive characteristics in semifree-ranging Barbary macaques (Macaca sylvanus L. 1758). Folia Primatologica, 43, 69-83.

Lee, P. C. (1996). The meanings of weaning: growth, lactation and life history. Evolutionary Anthropology, 5, 87-96.

Lee, P. C. (1999). Comparative ecology of postnatal growth and weaning among haplorhine primates. In P. C. Lee (Ed.), Comparative primate socioecology (pp. 111-139). Cambridge: Cambridge University Press.

Lee, P. C., \& Kappeler, P. M. (2003). Socioecological correlates of phenotypic plasticity of primate life histories. In P. M. Kappeler \& M. E. Pereira (Eds.), Primate life histories and socioecology (pp. 4165). Chicago: University of Chicago Press.

Lee, P. C., Majluf, P., \& Gordon, I. J. (1991). Growth, weaning and maternal investment from a comparative perspective. Journal of Zoology, 225, 99-114.

Lewis, R. J., \& Kappeler, P. M. (2005). Seasonality, body condition, and timing of reproduction in Propithecus verreauxi verreauxi in the Kirindy Forest. American Journal of Primatology, 67, 347-364.

Li, J. H., Yin, H. B., \& Wang, Q. S. (2005). Seasonality of reproduction and sexual activity in female Tibetan macaques (Macaca thibetana) at Huangshan, China. Acta Zoologica Sinica, 51, 365-375.

Lindburg, D. G. (1971). The rhesus monkey in north India; an ecological and behavioral study. In L. A. Rosenblum (Ed.), Primate behavior: Development in field and laboratory research (Vol. 2, pp. 1106). New York: Academic Press.

Maninger, N., Sackett, G. P., \& Ruppenthal, G. C. (2000). Weaning, body weight, and postpartum amenorrhea duration in pigtailed macaques (Macaca nemestrina). American Journal of Primatology, 52, 81-91.

McNeilly, A. S. (2001). Lactational control of reproduction. Reproduction, Fertility and Development, 13 (8), 583-590.

Melnick, D. J., \& Pearl, M. C. (1987). Cercopithecines in multimale groups: Genetic diversity and population structure. In B. B. Smuts, D. L. Cheney, R. M. Seyfarth, R. W. Wrangham, \& T. T. Struhsaker (Eds.), Primate societies (pp. 121-134). Chicago: University of Chicago Press.

Ménard, N., \& Vallet, D. (1996). Demography and ecology of Barbary macaques (Macaca sylvanus) in two different habitats. In J. E. Fa \& D. G. Lindburg (Eds.), Evolution and ecology of macaque societies (pp. 106-131). New York: Cambridge University Press.

Moehle, U., Heistermann, M., Dittami, J., Reinberg, V., Wallner, B., \& Hodges, J. K. (2005). Patterns of anogenital swelling size and their endocrine correlates during ovulatory cycles and early pregnancy in free-ranging Barbary macaques (Macaca sylvanus) of Gibraltar. American Journal of Primatology, 66, 351-368.

Nunn, C. (1999a). The number of males in primate social groups: a comparative test of the socioecological model. Behavioral Ecology and Sociobiology, 46, 1-13.

Nunn, C. (1999b). The evolution of exaggerated swellings in primates and the graded-signal hypothesis. Animal Behaviour, 58, 229-246.

Nunn, C., van Schaik, C. P., \& Zinner, D. (2001). Do exaggerated sexual swellings function in female mating competition in primates? A comparative test of the reliable indicator hypothesis. Behavioral Ecology, 12, 646-654.

Okamoto, K. (2000). Life history and demography of wild moor macaques (Macaca maurus): summary of ten years of observations. American Journal of Primatology, 52, 1-11.

O’Neill, A. C., Fedigan, L. M., \& Ziegler, T. E. (2004). Relationship between ovarian cycle phase and sexual behavior in female Japanese macaques (Macaca fuscata). American Journal of Physical Anthropology, 125, 352-362.

Ostner, J., Heistermann, M., \& Schülke, O. (2008). Dominance, aggression and physiological stress in wild male Assamese macaques (Macaca assamensis). Hormones and Behavior, 54, 613-619.

Pereira, M. E. (1991). Asynchrony within estrous synchrony among ringtailed lemurs (Primates: Lemuridae). Physiology \& Behavior, 49, 47-52.

Robbins, M. M., Robbins, A. M., Gerald-Steklis, N., \& Steklis, H. D. (2007). Socioecological influences on the reproductive success of female mountain gorillas (Gorilla beringei beringei). Behavioral Ecology and Sociobiology, 61, 919-931. 
Setchell, J. M., Lee, P. C., Wickings, E. J., \& Dixson, A. F. (2002). Reproductive parameters and maternal investment in mandrills (Mandrillus sphinx). International Journal of Primatology, 23, 51-68.

Shideler, S. E., Orturo, A. M., Moran, F. M., Moorman, E. A., \& Lasley, B. L. (1993). Simple extraction and enzyme immunoassays for estrogen and progesterone metabolites in the feces of Macaca fascicularis during non-conceptive and conceptive ovarian cycles. Biology of Reproduction, 48, $1290-1298$.

Strier, K. B., \& Ziegler, T. E. (1997). Behavioral and endocrine characteristics of the reproductive cycle in wild muriqui Monkeys, Brachyteles arachnoides. American Journal of Primatology, 42, 299-310.

Takahata, Y. (1980). The reproductive biology of a free-ranging troop of Japanese monkeys. Primates, 21, 303-329.

Takahata, Y., Suzuki, S., Agetsuma, N., Okayasu, N., Sugiura, H., Takahashi, H., et al. (1998). Reproduction of wild Japanese macaque females of Yakushima and Kinkazan Islands: a preliminary report. Primates, 39, 339-349.

Tanaka, T., Tokuda, K., \& Kotera, S. (1970). Effects of infant loss on the interbirth interval of Japanese monkeys. Primates, 11, 113-117.

Thierry, B. (2007). The macaques: A double-layered social organization. In C. Campbell, A. Fuentes, \& K. MacKinnon (Eds.), Primates in perspective (pp. 224-239). Oxford: Oxford University Press.

Thierry, B., Iwaniuk, A. N., \& Pellis, S. M. (2000). The influence of phylogeny on the social behaviour of macaques (Primates: Cercopithecidae, genus Macaca). Ethology, 106, 713-728.

van Noordwijk, M. A. (1985). Sexual behaviour of Sumatran long-tailed macaques (Macaca fascicularis). Zeitschrift für Tierpsychologie, 70, 277-296.

van Noordwijk, M. A., \& van Schaik, C. P. (2004). Sexual selection and the careers of primate males: Paternity concentration, dominance-acquisition tactics and transfer decisions. In P. M. Kappeler \& C. P. van Schaik (Eds.), Sexual selection in primates: New and comparative perspectives (pp. 208-229). Cambridge: Cambridge University Press.

van Schaik, C. P., van Noordwijk, M. A., \& Nunn, C. L. (1999). Sex and social evolution in primates. In P. C. Lee (Ed.), Comparative primate socioecology (pp. 204-231). Cambridge: Cambridge University Press.

Walker, M. L., Gordon, T. P., \& Wilson, M. E. (1983). Menstrual cycle characteristics of seasonally breeding rhesus monkeys. Biology of Reproduction, 29, 841-848.

Wehrenberg, W. B., Dyrenfurth, I., \& Ferin, M. (1980). Endocrine characteristics of the menstrual cycle in the Assamese monkey (Macaca assamensis). Biology of Reproduction, 23, 522-525.

Zhao, Q. K., \& Deng, Z. Y. (1988). Macaca thibetana at Mt. Emei, China: II. Birth seasonality. American Journal of Primatology, 16, 261-268.

Ziegler, T., Hodges, K., Winkler, P., \& Heistermann, M. (2000). Hormonal correlates of reproductive seasonality in wild Hanuman langurs (Presbytis entellus). American Journal of Primatology, 51, 119134.

Zinner, D., Schwibbe, M. H., \& Kaumanns, W. (1994). Cycle synchrony and probability of conception in female hamadryas baboons Papio hamadryas. Behavioral Ecology and Sociobiology, 35, 175-183. 